\title{
FLORÍSTICA E ESTRUTURA HORIZONTAL DA VEGETAÇÃO ARBÓREA DE UMA RAVINA EM UM FRAGMENTO FLORESTAL NO MUNICÍPIO DE VIÇOSA, MG'
}

\author{
Érica Pereira de Campos², Alexandre Francisco da Silvaª , João Augusto Alves Meira Neto ${ }^{3}$ e Sebastião \\ Venâncio Martins ${ }^{4}$
}

\begin{abstract}
RESUMO - Este estudo foi desenvolvido em um trecho de um fragmento de Floresta Estacional Semidecídua Montana, no Sítio Bom Sucesso, em Viçosa, MG. O objetivo deste trabalho foi conhecer a composição florística e a estrutura fitossociológica do componente arbóreo. Foram instalados 10 transectos de 50 x $10 \mathrm{~m}$, subdivididos em cinco parcelas de $10 \times 10 \mathrm{~m}$ cada um, totalizando 50 parcelas em $5.000 \mathrm{~m}^{2}$. Foram incluídos na amostragem todos os indivíduos arbóreos que apresentavam, no mínimo, $15 \mathrm{~cm}$ de circunferência do tronco, a $130 \mathrm{~cm}$ do solo. Foram identificadas 151 espécies pertencentes a 108 gêneros de 45 famílias botânicas e amostrados, em 0,5 ha, 820 indivíduos arbóreos vivos e 32 mortos em pé, o que significou uma densidade total estimada de 1.704 indivíduos/ha. A área basal/ha foi de $38,450 \mathrm{~m}^{2}$ e a altura média, de $8,43 \mathrm{~m}$. Euterpe edulis foi o destaque da estrutura da vegetação estudada, com 314 indivíduos amostrados, resultando numa densidade relativa de $37,38 \%$, frequêencia absoluta de $90 \%$, frequiência relativa de $8,91 \%$, e dominância relativa de $18,79 \%$. O índice de diversidade de Shannon foi de 3,52 e a eqüabilidade, igual a 0,696. Os resultados da composição florística e da estrutura fitossociológica indicaram alta riqueza e diversidade média, sendo a maior parte das espécies representada por poucos indivíduos.
\end{abstract}

Palavras-chave: Composição florística, estrutura fitossociológica e Floresta Estacional Semidecídua.

\section{FLORISTICS AND HORIZONTAL STRUCTURE OF THE TREE VEGETATION OF A RAVINE IN A FOREST FRAGMENT IN THE MUNICIPALITY OF VIÇOSA, MG}

\begin{abstract}
This study was developed in a section of a Montane Seasonal Semideciduous Forest fragment, in the Bom Sucesso Farm, Viçosa-MG-Brazil. This study aimed at finding out about the floristic composition and the phytosociologic structure of the tree component. Ten transects of 50x10m, subdivided into 5 plots of $10 \times 10 \mathrm{~m}$ each, totalling 50 plots within $5000 \mathrm{~m}^{2}$ were established. In the sampling, all the tree individuals with a minimum of $15 \mathrm{~cm}$ of stem circunference at $130 \mathrm{~cm}$ above ground were evaluated. A total of 151 species pertaining to 108 genera of 45 botanic families were identified. Within 0.5 ha, 820 alive trees and 32 dead standing up trees were sampled, which means a total density of 1704 individuals/ha. The basal area/ hectare was $38.450 \mathrm{~m}^{2}$ and the average height was $8.43 \mathrm{~m}$. The species Euterpe edulis was prominent in the structure of the studied vegetation, with 314 individuals sampled, resulting in a relative density of $37.38 \%$, absolute frequency of $90 \%$, relative frequency $(F R)$ of $8.91 \%$, relative dominance of $18.79 \%$. The Shannon diversity index was 3.52 and the equability was 0.696. The result of floristic composition and phytosociologic structure showed high richness and medium diversity, although most of the species were represented by few individuals.
\end{abstract}

Keywords: Floristic composition, phytosociologic structure and Seasonal Semidecidous Forest.

\footnotetext{
${ }^{1}$ Recebido em 09.03.06 e aceito para publicação em 18.09.2006.

2 Programa de Pós-Graduação em Biologia Vegetal da Universidade Federal de Viçosa. E-mail: <camposep@ig.com.br>.

${ }^{3}$ Departamento de Biologia Vegetal da UFV. E-mail: <j.meira@ufv.br $>$.

${ }^{4}$ Departamento de Engenharia Florestal da UFV. E-mail: <venancio@ufv.br>.
} 


\section{INTRODUÇÃO}

A Zona da Mata mineira, localizada dentro dos limites da Floresta Atlântica que, segundo Aubréville (1959), formava um continuum florestal desde o litoral do Estado do Espírito Santo até as proximidades de Belo Horizonte, foi alvo da ação antrópica desde a metade do século XIX, sendo a floresta substituída principalmente pela cultura do café e por pastagens (PANIAGO, 1984).

O padrão de distribuição da vegetação da Zona da Mata mineira apresenta-se predominantemente, na forma de pequenos fragmentos florestais, confinados a topos de morros e terrenos com grande declividade.

A fragmentação florestal gera "ilhas de vegetação" de diferentes tamanhos, formas e graus de isolamento, comprometendo a composição, a estrutura e a dinâmica da vegetação, sendo a perda da biodiversidade o principal impacto ambiental desse processo (VIANA, 1990).

Estudos sobre a composição da vegetação brasileira tiveram um avanço significativo nos últimos 10 anos. No entanto, são poucos, quando se sabe que existem vastas áreas do território brasileiro ainda desconhecidas e outras conhecidas incipientemente, como a Zona da Mata de Minas Gerais, onde se podem citar os trabalhos realizados por Silva et al. (2000), Meira Neto e Martins (2002), Marangon et al. (2003), Ribas et al. (2003) e Silva et al. (2004).

Trabalhos de cunhos florístico e fitossociológico são fundamentais à medida que geram subsídios para o manejo da comunidade, possibilitando traçar estratégias de conservação da diversidade (ALMEIDA e SOUZA, 1997), além de contribuírem para o mapeamento e fornecimento de dados sobre os remanescentes de vegetação.

Meira Neto e Martins (2000) consideraram que trabalhos sobre a estrutura da vegetação são importantes para o conhecimento das comunidades vegetais fragmentadas, pois ocorrem em ampla gama de situações ambientais, com diferentes faces de exposição solar, tipos de solo e condições de umidade, além daquelas geradas pela ação antrópica.

De acordo com o exposto, este trabalho teve como objetivo conhecer a composição florística e a estrutura fitossociológica de um trecho de floresta situada nas encostas de uma ravina no Município de Viçosa, fornecendo informações que podem subsidiar estudos futuros sobre as formações florestais no Estado de Minas Gerais.

\section{MATERIAL E MÉTODOS}

O Município de Viçosa situa-se nas coordenadas $20^{\circ} 45^{\prime} \mathrm{S}$ e $42^{\circ} 55^{\prime} \mathrm{W}$, no sudeste do Estado de Minas Gerais, em região caracteristicamente montanhosa, de topografia acidentada, com vales estreitos e úmidos.

O clima da região é do tipo $\mathrm{Cwb}$, subtropical moderado úmido, segundo a classificação de Köppen. Há duas estações bem demarcadas, uma chuvosa de outubro a março e outra sem chuvas significativas entre abril e setembro. As médias anuais de precipitação, umidade relativa e temperatura do ar são, respectivamente, de $1221,4 \mathrm{~mm}, 81 \%$ e $19,4^{\circ} \mathrm{C}$, sendo a média das máximas de $26,4{ }^{\circ} \mathrm{C}$ e a média das mínimas de $14,8{ }^{\circ} \mathrm{C}$ (DEPARTAMENTO ..., 1992).

O fragmento estudado, com cerca de 35 ha, que pertence à Formação da Floresta Estacional Semidecidual Montana (VELOSO et al., 1991), está localizado em uma propriedade particular, de mesma posse há 120 anos, conhecida como Sítio Bom Sucesso. Segundo seus proprietários, nunca houve corte raso ou plantios na área; somente retirada esporádica, no passado, de árvores para utilização como lenha.

O local da amostragem está em altitude de 742 $\mathrm{m}$, situado numa ravina, ou seja, toposseqüência formada quando a quantidade de água que cai no solo é maior do que a sua capacidade de infiltração, o que resulta num escoamento superficial provocando incisões sobre o solo, formando canais contínuos, estreitos e de pouca profundidade (GUERRA e CUNHA, 1995).

Para a amostragem fitossociológica, utilizou-se o método de parcelas (MUELLER-DOMBOIS e ELLENBERG, 1974). Foram estabelecidos 10 transectos de $50 \times 10 \mathrm{~m}$ cada, eqüidistantes $10 \mathrm{~m}$, subdivididos em cinco parcelas de $10 \times 10$ m cada, totalizando 5.000 $\mathrm{m}^{2}$. Os transectos foram montados perpendicularmente em relação ao curso de uma ravina natural, estendendose $25 \mathrm{~m}$ para cada lado da encosta e tomando-se o centro da ravina como referência.

Foram amostrados todos os indivíduos arbóreos, inclusive os mortos ainda em pé, que apresentavam no mínimo $15 \mathrm{~cm}$ de circunferência do tronco a 1,30 $\mathrm{m}$ do solo (CAP). De cada indivíduo foram anotadas 
a CAP, a altura total e as características das plantas e coletadas amostras de material botânico para auxiliar a determinação taxonômica, sendo que o material fértil foi incorporado ao Herbário do Departamento de Biologia Vegetal da Universidade Federal de Viçosa (VIC).

O período de amostragem foi realizado de outubro de 2000 a novembro de 2001, sendo a estrutura horizontal avaliada entre os meses de outubro de 2000 a abril de 2001 e a composição florística para a coleta de material fértil ao longo de todo o período estudado.

Os parâmetros fitossociológicos foram estimados pelo programa FITOPAC 1 (SHEPHERD, 1996) e interpretados segundo as proposições de MuellerDombois e Ellenberg (1974). A diversidade florística foi estimada pelo índice de diversidade de Shannon (H') (BROEWER e ZAR, 1984) e a equabilidade pelo coeficiente de equabilidade de Pielou (J) (PIELOU, 1975).

A composição florística foi avaliada a partir da amostragem fitossociológica.

O sistema de classificação utilizado foi o de Cronquist (1988), exceto para a família Leguminosae, para a qual foram mantidas as três subfamílias. Os nomes das espécies foram confirmados e atualizados pelo site do Missouri Botanical Garden (2006) ou por meio de literatura mais recente. Os nomes dos autores seguiram a padronização recomendada por Brumitt e Powell (1992).

\section{RESULTADOS E DISCUSSÃO}

No levantamento florístico foram encontradas 151 espécies, pertencentes a 108 gêneros de 45 famílias botânicas.

As famílias mais ricas foram: Leguminosae (15), Myrtaceae e Lauraceae (14 cada uma), Euphorbiaceae e Rubiaceae (10 cada uma), Meliaceae (9), Flacourtiaceae, Annonaceae e Moraceae (seis cada uma) e Apocynaceae (5).

Os gêneros mais ricos foram: Myrcia, com cinco espécies; Casearia, Eugenia, Inga, Ocotea e Trichilia com quatro cada; e Tapirira, Aspidosperma, Cróton e Guarea, com três espécies cada.

Os resultados obtidos indicaram que o trecho do fragmento estudado apresentou alta riqueza florística nos três níveis hierárquicos: espécies, gêneros e famílias, quando comparados com outros trabalhos realizados na região, indicando o alto grau de preservação do fragmento. Ressalta-se que as árvores não identificadas até o nível de espécie não floresceram durante o período de desenvolvimento do trabalho.

Entre as famílias mais ricas e mais comumente encontradas na microrregião de Viçosa, destacam-se Leguminosae, Myrtaceae, Lauraceae, Euphorbiaceae, Rubiaceae e Flacourtiaceae. Entre estas, as três primeiras destacaram-se em todos os levantamentos avaliados (Quadro 1), sugerindo suas importâncias em relação à representatividade qualquer que seja o histórico da área analisada. As famílias Carycaceae, Icacinaceae e Lythraceae, registradas neste estudo, constituemse na primeira citação para a zona da Mata de Minas Gerais

Foram analisadas as listas florísticas de 15 trabalhos realizados na Zona da Mata: Volpato (1994), Almeida e Souza (1997), Meira Neto et al. (1997abc; 1998), Marangon (1999), Paula (1999), Gomes (2000), Senra (2000), Silva et al. (2000), Soares Júnior (2000), Ribas et al. (2003), Lopes et al. (2002) e Meira Neto e Martins (2002). Comparando essas listas com a do presente trabalho, verificou-se que 24 espécies foram relacionadas somente no presente estudo; são elas: Aiouea trinervis, Alsophila sternbergii, Bathysa cuspidata, Celtis iguanae, Chrysophylum lucentifolium, Clusia arrudea, Cyathea delgadii, Duguetia lanceolata, Endlicheria glomerata, Eugenia cerasifolia, Guapira hirsuta, Hyeronima ferruginea, Inga laurina, Lafoensia glyptocarpa, Lecythis lurida, Maytenus evonymoides, Mouriria glazioviana, Pouroma guianensis, Psychotria nuda, Qualea gestasiana, Rudgea myrsinifolia, Tapirira marchandii, Urera baccifera e Virola gardineri. Aliada ao número de espécies exclusivas contempladas neste estudo está a riqueza encontrada na área total da amostra (0,5 ha), em comparação com outros trabalhos realizados em fragmentos da microrregião.

Os resultados fitossociológicos indicaram que em $5.000 \mathrm{~m}^{2}$ foram amostrados 820 indivíduos arbóreos vivos e 32 mortos em pé, perfazendo um total de 852 , o que significou uma densidade total estimada de 1.704 indivíduos por hectare. A altura média individual foi de $8,43 \mathrm{~m}$ e a área basal total, $19,225 \mathrm{~m}^{2}$ ou 38,450 $\mathrm{m}^{2}$.ha ${ }^{-1}$, um dos maiores valores encontrados na região.

Silva et al. (2000), estudando um hectare de Floresta Estacional Semidecídua Montana no Município de Viçosa, encontraram 1.653 indivíduos por hectare e área basal total de 26,73 m²; Meira Neto e Martins (2000), adotando

R. Árvore, Viçosa-MG, v.30, n.6, p.1045-1054, 2006 
o critério de inclusão de $10 \mathrm{~cm}$ de circunferência à altura do peito (CAP), acharam 2.064 indivíduos por hectare e área basal de $29,83 \mathrm{~m}^{2}$, em um fragmento florestal em estágio secundário de regeneração no Município de Viçosa, enquanto Sevilha et al. (2001), 1.639 indivíduos por hectare e área basal total estimada de $31,6 \mathrm{~m}^{2}$.

Na estrutura da vegetação estudada (Quadro 2), destacou-se a forte predominância de Euterpe edulis, com 314 indivíduos amostrados, resultando numa densidade relativa (DR) de $37,38 \%$, frequiências absoluta (FA) e relativa (FR) de 90 e $8,91 \%$, respectivamente, e dominância relativa (DoR) igual a $18,79 \%$. Seus valores de cobertura (VC) e de importância (VI) foram de $21,70 \%$ e $28,09 \%$, respectivamente.

Além de Euterpe edulis, as espécies que apresentaram os maiores valores de importância foram: Sorocea bonplandii, Guarea macrophylla, Sterculia chicha, Virola oleifera, Aspidosperma cylindrocarpon, Protium warmingianum, Guapira opposita, Croton hemiargireus, Eugenia leptoclada e Siparuna guianensis.
Aspidosperma cylindrocarpon foi representada por apenas um indivíduo. No entanto, ocupou a sétima posição em valor de importância, devido à sua grande biomassa, resultado de uma área basal alta e, conseqüentemente, das dominâncias absoluta e relativa. Essa mesma espécie ocupou o quarto lugar em valor de cobertura, maior do que de outras, que se apresentaram com número bem maior de indivíduos, o que mostra a grande influência de sua dominância.

Sterculia chicha e Virola oleifera, que são espécies de grande porte, também estavam entre os maiores valores de dominâncias relativa e absoluta.

Sorocea bonplandii e Guarea macrophylla ocuparam as primeiras posições devido às suas densidades e freqüências. A primeira espécie apresentou (DA) igual a 48 e (DR) de $2,86 \%$, (FA) igual a $38 \%$ e (FR) igual a $3,76 \%$, enquanto a segunda espécie, (DA) igual a 46 e (DR) de $2,74 \%$ e (FA) igual a $32 \%$ e (FR) $3,17 \%$. Sorocea bonplandii, apesar de ter se apresentado entre as maiores densidades e freqüências, não se destacou em dominância, já que não teve indivíduos de grande porte, estando limitada ao estrato médio.

Quadro 1 - Dados florísticos de alguns estudos realizados na microrregião de Viçosa, MG, com indicação da circunferência mínima do tronco $(\mathrm{CAP} / \mathrm{cm})$, área da amostra (AR/ha), números de espécies (NE), gêneros (NG) e famílias (NF), listando as famílias mais ricas (mínimo de cinco espécies) de cada levantamento; o número que segue o nome da família corresponde ao número de espécies

Table 1 - Floristics data of some studies carried out in a micro region of Viçosa - MG, with indication of minimum stem circunference $(C A P / \mathrm{cm})$, area of sample $(A R / h a)$, number of species $(N E)$, genus $(N G)$ and family $(N F)$, listing the richest (minimum of five species) of each study; the number that follow the name of the family correspond the number of species

\begin{tabular}{|c|c|c|c|c|c|c|}
\hline Levantamentos & CAP & $\mathrm{AR}$ & $\mathrm{NE}$ & NG & $\mathrm{NF}$ & Famílias \\
\hline Este estudo & 15 & 0,5 & 151 & 106 & 46 & $\begin{array}{l}\text { Leguminosae (15), Myrtaceae (14), Lauraceae (14), } \\
\text { Euphorbiaceae (10), Rubiaceae (10), Meliacae (9), } \\
\text { Flacourtiaceae (6), Annonaceae (6), } \\
\text { Moraceae (6), Apocynaceae (6) }\end{array}$ \\
\hline Volpato (1994) & 15 & 1,2 & 95 & 75 & 34 & $\begin{array}{l}\text { Leguminosae (9), Euphorbiaceae (8), Rubiaceae (7), } \\
\text { Lauraceae (6), Sapindaceae (5), Myrtaceae (5) }\end{array}$ \\
\hline Marangon (1999) & 15 & 1,0 & 147 & 134 & 51 & $\begin{array}{l}\text { Leguminosae (38), Myrtaceae (11), } \\
\text { Euphorbiaceae (10), Lauraceae (10), Meliaceae (10), } \\
\text { Rubiaceae (10), Annonaceae (7), Flacourtiaceae (7), } \\
\text { Solanaceae (7), Sapindaceae (6), Apocynaceae (5), } \\
\text { Bignoniaceae (5), Moraceae (5) }\end{array}$ \\
\hline $\begin{array}{l}\text { Meira-Neto e Martins } \\
(2002)\end{array}$ & 10 & 1,0 & 154 & 105 & 45 & $\begin{array}{l}\text { Leguminosae (26), Rubiaceae (16), Lauraceae (10), } \\
\text { Euphorbiaceae (9), Myrtaceae (9), Annonaceae (6), } \\
\text { Flacourtiaceae (6), Melastomataceae (6), Rutaceae (5) }\end{array}$ \\
\hline Senra (2000) & 15 & 1,0 & 105 & 75 & 37 & $\begin{array}{l}\text { Leguminosae (17), Annonaceae (9), } \\
\text { Euphorbiaceae (8), Lauraceae (7), Myrtaceae (5), } \\
\text { Flacourtiaceae (6), Sapindaceae (6) }\end{array}$ \\
\hline Silva et al. (2000) & 15 & 1,0 & 91 & 77 & 34 & $\begin{array}{l}\text { Leguminosae (16), Myrtaceae (6), Rubiaceae (6), } \\
\text { Lauraceae (6), Flacourtiaceae (5) }\end{array}$ \\
\hline Lopes et al. (2002) & 15 & 1,0 & 121 & 89 & 38 & $\begin{array}{l}\text { Leguminosae (20), Lauraceae (10), Rubiaceae (9), } \\
\text { Flacourtiaceae (8), Myrtaceae (7), Euphorbiaceae (6) }\end{array}$ \\
\hline
\end{tabular}

R. Árvore, Viçosa-MG, v.30, n.6, p.1045-1054, 2006 
Quadro 2 - Parâmetros fitossociológicos das espécies arbóreas do Sítio Bom Sucesso, Viçosa - MG, ordenados decrescentemente pelo valor de importância (VI): número de indivíduos (NI), densidade absoluta (DA), densidade relativa (DR), freqüência absoluta (FA), freqüência relativa (FR), dominância absoluta (DoA), dominância relativa (DoR) e valor de cobertura (VC)

Table 2 - Phytosociological parameters of arboreal species of Bom Sucesso Farm, Viçosa-MG, showing a decreasing order of Importance Value (VI): number of individuals (NI), absolute density (DA), relative density (DR), absolute frequency $(F A)$, relative frequency $(F R)$, absolute dominance $(D o A)$, relative dominance $(D o R)$ and covering value $(V C)$

\begin{tabular}{|c|c|c|c|c|c|c|c|c|c|}
\hline Espécie & $\mathrm{NI}$ & DA & DR & FA & FR & DoA & DoR & $\mathrm{VC} \%$ & $\mathrm{VI} \%$ \\
\hline Euterpe edulis & 314 & 628 & 37,38 & 90 & 8,91 & 7,2261 & 18,79 & 21,70 & 28,09 \\
\hline Mortas & 32 & 64 & 3,81 & 52 & 5,15 & 1,4292 & 3,72 & 3,77 & 4,23 \\
\hline Sorocea bonplandii & 24 & 48 & 2,86 & 38 & 3,76 & 0,5206 & 1,35 & 2,11 & 2,66 \\
\hline Guarea macrophylla & 23 & 46 & 2,74 & 32 & 3,17 & 0,6817 & 1,77 & 2,26 & 2,56 \\
\hline Sterculia chicha & 12 & 24 & 1,43 & 14 & 1,39 & 1,8132 & 4,72 & 3,07 & 2,51 \\
\hline Virola oleifera & 8 & 16 & 0,95 & 14 & 1,39 & 1,7146 & 4,46 & 2,71 & 2,27 \\
\hline Aspidosperma cylindrocarpon & 1 & 2 & 0,12 & 2 & 0,2 & 2,1672 & 5,64 & 2,88 & 1,98 \\
\hline Protium warmingianum & 17 & 34 & 2,02 & 26 & 2,57 & 0,3723 & 0,97 & 1,50 & 1,86 \\
\hline Guapira opposita & 17 & 34 & 2,02 & 26 & 2,57 & 0,2437 & 0,63 & 1,33 & 1,74 \\
\hline Croton hemiargyreus & 9 & 18 & 1,07 & 16 & 1,58 & 0,9565 & 2,49 & 1,78 & 1,71 \\
\hline Eugenia leptoclaca & 16 & 32 & 1,9 & 28 & 2,77 & 0,1298 & 0,34 & 1,12 & 1,67 \\
\hline Siparuna guianensis & 14 & 28 & 1,67 & 24 & 2,38 & 0,0764 & 0,2 & 0,94 & 1,41 \\
\hline Myrcia sp. 1 & 7 & 14 & 0,83 & 12 & 1,19 & 0,7711 & 2,01 & 1,42 & 1,34 \\
\hline Colubrina glandulosa & 6 & 12 & 0,71 & 10 & 0,99 & 0,8214 & 2,14 & 1,43 & 1,28 \\
\hline Apuleia leiocarpa & 6 & 12 & 0,71 & 12 & 1,19 & 0,724 & 1,88 & 1,30 & 1,26 \\
\hline Tapiria obtusa & 7 & 14 & 0,83 & 14 & 1,39 & 0,5891 & 1,53 & 1,19 & 1,25 \\
\hline Machaerium nictitans & 5 & 10 & 0,6 & 10 & 0,99 & 0,7247 & 1,88 & 1,24 & 1,16 \\
\hline Annona cacans & 7 & 14 & 0,83 & 14 & 1,39 & 0,4346 & 1,13 & 0,98 & 1,12 \\
\hline Astronium fraxinifolium & 3 & 6 & 0,36 & 6 & 0,59 & 0,9169 & 2,38 & 1,37 & 1,11 \\
\hline Nectandra lanceolata & 5 & 10 & 0,6 & 10 & 0,99 & 0,6692 & 1,74 & 1,17 & 1,11 \\
\hline Ficus insipida & 6 & 12 & 0,71 & 10 & 0,99 & 0,5827 & 1,52 & 1,12 & 1,07 \\
\hline Maclura tinctoria & 7 & 14 & 0,83 & 14 & 1,39 & 0,2658 & 0,69 & 0,76 & 0,97 \\
\hline Ocotea odorifera & 7 & 14 & 0,83 & 12 & 1,19 & 0,3293 & 0,86 & 0,85 & 0,96 \\
\hline Cordia sellowiana & 7 & 14 & 0,83 & 12 & 1,19 & 0,3093 & 0,8 & 0,82 & 0,94 \\
\hline Hyeronima ferruginea & 2 & 4 & 0,24 & 4 & 0,4 & 0,7277 & 1,89 & 1,07 & 0,84 \\
\hline Nectandra oppositifolia & 4 & 8 & 0,48 & 8 & 0,79 & 0,4549 & 1,18 & 0,83 & 0,82 \\
\hline Inga cylindrica & 7 & 14 & 0,83 & 10 & 0,99 & 0,209 & 0,54 & 0,69 & 0,79 \\
\hline Inga striata & 4 & 8 & 0,48 & 8 & 0,79 & 0,4104 & 1,07 & 0,77 & 0,78 \\
\hline Tovomitopsis saldanhae & 5 & 10 & 0,6 & 10 & 0,99 & 0,242 & 0,63 & 0,61 & 0,74 \\
\hline Coussapoa microcarpa & 2 & 4 & 0,24 & 4 & 0,4 & 0,5883 & 1,53 & 0,89 & 0,72 \\
\hline Luehea grandiflora & 4 & 8 & 0,48 & 6 & 0,59 & 0,3939 & 1,02 & 0,75 & 0,70 \\
\hline Simira sampaioana & 4 & 8 & 0,48 & 8 & 0,79 & 0,272 & 0,71 & 0,59 & 0,66 \\
\hline Cryptocaria moschata & 2 & 4 & 0,24 & 4 & 0,4 & 0,5017 & 1,3 & 0,77 & 0,65 \\
\hline Scheflera morototonii & 4 & 8 & 0,48 & 8 & 0,79 & 0,1944 & 0,51 & 0,49 & 0,59 \\
\hline Hieronima alchorneoides & 1 & 2 & 0,12 & 2 & 0,2 & 0,5565 & 1,45 & 0,79 & 0,59 \\
\hline Rollinia laurifolia & 3 & 6 & 0,36 & 4 & 0,4 & 0,3829 & 1 & 0,68 & 0,58 \\
\hline Bathysa nicholsonii & 5 & 10 & 0,6 & 8 & 0,79 & 0,1366 & 0,36 & 0,48 & 0,58 \\
\hline Eriotheca candoleana & 4 & 8 & 0,48 & 8 & 0,79 & 0,1821 & 0,47 & 0,48 & 0,58 \\
\hline Citronella megaphylla & 5 & 10 & 0,6 & 10 & 0,99 & 0,0504 & 0,13 & 0,37 & 0,57 \\
\hline Trichilia elegans & 6 & 12 & 0,71 & 8 & 0,79 & 0,0635 & 0,17 & 0,44 & 0,56 \\
\hline Ocotea lanceolata & 1 & 2 & 0,12 & 2 & 0,2 & 0,5157 & 1,34 & 0,73 & 0,55 \\
\hline Cecropia hololeuca & 2 & 4 & 0,24 & 4 & 0,4 & 0,3894 & 1,01 & 0,63 & 0,55 \\
\hline Brosimum glaziovii & 4 & 8 & 0,48 & 6 & 0,59 & 0,1729 & 0,37 & 0,42 & 0,55 \\
\hline Peschiera laeta & 1 & 2 & 0,12 & 2 & 0,2 & 0,4986 & 1,3 & 0,71 & 0,54 \\
\hline Calyptranthes brasiliensis & 4 & 8 & 0,48 & 8 & 0,79 & 0,1194 & 0,31 & 0,40 & 0,53 \\
\hline
\end{tabular}


Quadro 2 - Cont.

Table 2 - Cont.

\begin{tabular}{|c|c|c|c|c|c|c|c|c|c|}
\hline Espécie & $\mathrm{NI}$ & $\mathrm{DA}$ & DR & FA & FR & DoA & DoR & $\mathrm{VC} \%$ & VI\% \\
\hline Jacaranda macrantha & 4 & 8 & 0,48 & 8 & 0,79 & 0,1102 & 0,29 & 0,38 & 0,52 \\
\hline Cedrela fissilis & 2 & 4 & 0,24 & 4 & 0,4 & 0,3534 & 0,92 & 0,58 & 0,52 \\
\hline Rollinia silvatica & 4 & 8 & 0,48 & 6 & 0,59 & 0,1842 & 0,48 & 0,48 & 0,52 \\
\hline Myrtaceae sp. 1 & 5 & 10 & 0,6 & 8 & 0,79 & 0,0613 & 0,16 & 0,38 & 0,52 \\
\hline Rudgea myrsinifolia & 3 & 6 & 0,36 & 6 & 0,59 & 0,2204 & 0,57 & 0,47 & 0,51 \\
\hline Amaioua guianensis & 4 & 8 & 0,48 & 6 & 0,59 & 0,1729 & 0,45 & 0,47 & 0,51 \\
\hline Cabralea canjerana & 3 & 6 & 0,36 & 6 & 0,59 & 0,2181 & 0,57 & 0,46 & 0,51 \\
\hline Trichilia catigua & 4 & 8 & 0,48 & 8 & 0,79 & 0,0854 & 0,22 & 0,35 & 0,50 \\
\hline Casearia ulmifolia & 4 & 8 & 0,48 & 8 & 0,79 & 0,0741 & 0,19 & 0,34 & 0,49 \\
\hline Chrysophyllum gonocarpum & 3 & 6 & 0,36 & 6 & 0,59 & 0,1828 & 0,48 & 0,42 & 0,48 \\
\hline Lafoensia glyptocarpa & 3 & 6 & 0,36 & 6 & 0,59 & 0,1805 & 0,47 & 0,42 & 0,47 \\
\hline Swartzia myrtifolia var. elegans & 4 & 8 & 0,48 & 8 & 0,79 & 0,0571 & 0,15 & 0,31 & 0,47 \\
\hline Xylosma salzmanni & 4 & 8 & 0,48 & 8 & 0,79 & 0,0465 & 0,12 & 0,30 & 0,46 \\
\hline Pouteria caimito & 4 & 8 & 0,48 & 8 & 0,79 & 0,035 & 0,09 & 0,29 & 0,45 \\
\hline Marlierea sp. & 4 & 8 & 0,48 & 8 & 0,79 & 0,026 & 0,07 & 0,27 & 0,45 \\
\hline Casearia gossypiosperma & 2 & 4 & 0,24 & 4 & 0,4 & 0,2633 & 0,68 & 0,46 & 0,44 \\
\hline Bathysa cuspidata & 4 & 8 & 0,48 & 6 & 0,59 & 0,0918 & 0,24 & 0,36 & 0,44 \\
\hline Pausandra mouriniana & 1 & 2 & 0,12 & 2 & 0,2 & 0,3799 & 0,99 & 0,56 & 0,44 \\
\hline Inga laurina & 4 & 8 & 0,48 & 6 & 0,59 & 0,0893 & 0,23 & 0,36 & 0,43 \\
\hline Virola gardneri & 4 & 8 & 0,48 & 6 & 0,59 & 0,0815 & 0,21 & 0,35 & 0,43 \\
\hline Aniba firmula & 3 & 6 & 0,36 & 6 & 0,59 & 0,1097 & 0,29 & 0,32 & 0,41 \\
\hline Aniba laevigata & 2 & 4 & 0,24 & 4 & 0,4 & 0,2265 & 0,59 & 0,42 & 0,41 \\
\hline Piptocarpha macropoda & 2 & 4 & 0,24 & 4 & 0,4 & 0,2062 & 0,54 & 0,39 & 0,39 \\
\hline Inga capitata & 4 & 8 & 0,48 & 6 & 0,59 & 0,0202 & 0,05 & 0,27 & 0,37 \\
\hline Indeterminada I & 3 & 6 & 0,36 & 6 & 0,59 & 0,0366 & 0,1 & 0,23 & 0,35 \\
\hline Piptadenia paniculara & 2 & 4 & 0,24 & 4 & 0,4 & 0,1532 & 0,4 & 0,32 & 0,34 \\
\hline Trichilia emarginata & 3 & 6 & 0,36 & 6 & 0,59 & 0,0186 & 0,05 & 0,21 & 0,33 \\
\hline Campomanesia xantocarpa & 3 & 6 & 0,36 & 6 & 0,59 & 0,0181 & 0,05 & 0,20 & 0,33 \\
\hline Guatteria nigrescens & 3 & 6 & 0,36 & 4 & 0,4 & 0,0932 & 0,24 & 0,30 & 0,33 \\
\hline Pseudobombax grandiflorum & 1 & 2 & 0,12 & 2 & 0,2 & 0,2178 & 0,57 & 0,35 & 0,29 \\
\hline Piptadenia gonoacanta & 1 & 2 & 0,12 & 2 & 0,2 & 0,2105 & 0,55 & 0,34 & 0,29 \\
\hline Urera baccifera & 3 & 6 & 0,36 & 4 & 0,4 & 0,0411 & 0,11 & 0,23 & 0,29 \\
\hline Pera glabrata & 1 & 2 & 0,12 & 2 & 0,2 & 0,2087 & 0,54 & 0,33 & 0,29 \\
\hline Alchornea iricurana & 1 & 2 & 0,12 & 2 & 0,2 & 0,2032 & 0,53 & 0,33 & 0,28 \\
\hline Astrocarium aculeatissimum & 2 & 4 & 0,24 & 4 & 0,4 & 0,0797 & 0,21 & 0,23 & 0,28 \\
\hline Croton floribundus & 2 & 4 & 0,24 & 4 & 0,4 & 0,0673 & 0,17 & 0,21 & 0,27 \\
\hline Couratea hexandra & 2 & 4 & 0,24 & 4 & 0,4 & 0,0561 & 0,15 & 0,19 & 0,26 \\
\hline Chrysophyllum lucentifolium & 2 & 4 & 0,24 & 4 & 0,4 & 0,0448 & 0,12 & 0,18 & 0,25 \\
\hline Xylopia sericea & 2 & 4 & 0,24 & 4 & 0,4 & 0,0412 & 0,11 & 0,18 & 0,25 \\
\hline Indeterminada II & 3 & 6 & 0,36 & 2 & 0,2 & 0,0631 & 0,16 & 0,26 & 0,24 \\
\hline Endlicheria paniculata & 2 & 4 & 0,24 & 4 & 0,4 & 0,0321 & 0,08 & 0,16 & 0,24 \\
\hline Duguetia lanceolata & 2 & 4 & 0,24 & 4 & 0,4 & 0,0319 & 0,08 & 0,16 & 0,24 \\
\hline Anadenanthera colubrina & 2 & 4 & 0,24 & 4 & 0,4 & 0,0296 & 0,08 & 0,16 & 0,24 \\
\hline Clusea arrudea & 2 & 4 & 0,24 & 4 & 0,4 & 0,0285 & 0,07 & 0,16 & 0,24 \\
\hline Casearia sylvestris & 2 & 4 & 0,24 & 2 & 0,2 & 0,1032 & 0,27 & 0,26 & 0,23 \\
\hline Alchornea triplinervea & 1 & 2 & 0,12 & 2 & 0,2 & 0,1467 & 0,38 & 0,25 & 0,23 \\
\hline Pisonia ambigua & 2 & 4 & 0,24 & 4 & 0,4 & 0,0214 & 0,06 & 0,15 & 0,23 \\
\hline Casearia decandra & 2 & 4 & 0,24 & 4 & 0,4 & 0,021 & 0,05 & 0,15 & 0,23 \\
\hline Tabebuia chrysotricha & 2 & 4 & 0,24 & 4 & 0,4 & 0,0154 & 0,04 & 0,14 & 0,22 \\
\hline Dalbergia nigra & 2 & 4 & 0,24 & 4 & 0,4 & 0,015 & 0,04 & 0,14 & 0,22 \\
\hline Aspidosperma polyneuron & 2 & 4 & 0,24 & 4 & 0,4 & 0,0148 & 0,04 & 0,14 & 0,22 \\
\hline
\end{tabular}

R. Árvore, Viçosa-MG, v.30, n.6, p.1045-1054, 2006 
Quadro 2 - Cont.

Table 2-Cont.

\begin{tabular}{|c|c|c|c|c|c|c|c|c|c|}
\hline Espécie & $\mathrm{NI}$ & DA & $\mathrm{DR}$ & FA & FR & DoA & DoR & $\mathrm{VC} \%$ & $\mathrm{VI} \%$ \\
\hline Pouroma guianensis & 2 & 4 & 0,24 & 4 & 0,4 & 0,0146 & 0,04 & 0,14 & 0,22 \\
\hline Urbanodendron verrucossum & 2 & 4 & 0,24 & 4 & 0,4 & 0,0108 & 0,03 & 0,14 & 0,22 \\
\hline Marlierea cf obscura & 2 & 4 & 0,24 & 4 & 0,4 & 0,0098 & 0,03 & 0,13 & 0,22 \\
\hline Trichilia hirta & 2 & 4 & 0,24 & 4 & 0,4 & 0,0098 & 0,03 & 0,13 & 0,22 \\
\hline Terminalia $\mathrm{sp}$. & 1 & 2 & 0,12 & 2 & 0,2 & 0,1218 & 0,32 & 0,22 & 0,21 \\
\hline Brosimum glaziovii & 2 & 4 & 0,24 & 2 & 0,2 & 0,0519 & 0,13 & 0,19 & 0,19 \\
\hline Ficus glabra & 1 & 2 & 0,12 & 2 & 0,2 & 0,08 & 0,21 & 0,17 & 0,18 \\
\hline Micropholis venulosa & 1 & 2 & 0,12 & 2 & 0,2 & 0,0715 & 0,19 & 0,15 & 0,17 \\
\hline Psychotria conjugens & 2 & 4 & 0,24 & 2 & 0,2 & 0,0211 & 0,05 & 0,15 & 0,16 \\
\hline Acacia glomerosa & 1 & 2 & 0,12 & 2 & 0,2 & 0,0642 & 0,17 & 0,15 & 0,16 \\
\hline Lecythis lurida & 1 & 2 & 0,12 & 2 & 0,2 & 0,0642 & 0,17 & 0,15 & 0,16 \\
\hline Protium heptaphyllum & 1 & 2 & 0,12 & 2 & 0,2 & 0,0631 & 0,16 & 0,14 & 0,16 \\
\hline Alsophila sternbergii & 2 & 4 & 0,24 & 2 & 0,2 & 0,0169 & 0,04 & 0,14 & 0,16 \\
\hline Simaroubaceae sp. 1 & 2 & 4 & 0,24 & 2 & 0,2 & 0,0146 & 0,04 & 0,14 & 0,16 \\
\hline Sapium glandulatum & 1 & 2 & 0,12 & 2 & 0,2 & 0,0554 & 0,14 & 0,13 & 0,15 \\
\hline Myrcia sphaerocarpa & 2 & 4 & 0,24 & 2 & 0,2 & 0,0085 & 0,02 & 0,13 & 0,15 \\
\hline Sloanea monosperma & 1 & 2 & 0,12 & 2 & 0,2 & 0,0535 & 0,14 & 0,13 & 0,15 \\
\hline Celtis iguinae & 1 & 2 & 0,12 & 2 & 0,2 & 0,0503 & 0,13 & 0,13 & 0,15 \\
\hline Aspidosperma subincanum & 1 & 2 & 0,12 & 2 & 0,2 & 0,0499 & 0,13 & 0,13 & 0,15 \\
\hline Eugenia dodoneaefolia & 1 & 2 & 0,12 & 2 & 0,2 & 0,0447 & 0,12 & 0,12 & 0,14 \\
\hline Cyathea delgadii & 1 & 2 & 0,12 & 2 & 0,2 & 0,0414 & 0,11 & 0,12 & 0,14 \\
\hline Qualea gestaseana & 1 & 2 & 0,12 & 2 & 0,2 & 0,0352 & 0,09 & 0,11 & 0,14 \\
\hline Hymenaea courbaril & 1 & 2 & 0,12 & 2 & 0,2 & 0,0352 & 0,09 & 0,11 & 0,14 \\
\hline Guettarda viburnoides & 1 & 2 & 0,12 & 2 & 0,2 & 0,0337 & 0,09 & 0,11 & 0,13 \\
\hline Terminalia brasiliensis & 1 & 2 & 0,12 & 2 & 0,2 & 0,0317 & 0,08 & 0,10 & 0,13 \\
\hline Randia armata & 1 & 2 & 0,12 & 2 & 0,2 & 0,0268 & 0,07 & 0,10 & 0,13 \\
\hline Cupania tenuivalvis & 1 & 2 & 0,12 & 2 & 0,2 & 0,0255 & 0,07 & 0,10 & 0,13 \\
\hline Myrciaria sp. & 1 & 2 & 0,12 & 2 & 0,2 & 0,0235 & 0,06 & 0,09 & 0,13 \\
\hline Mouriria glazioviana & 1 & 2 & 0,12 & 2 & 0,2 & 0,0218 & 0,06 & 0,09 & 0,12 \\
\hline Ceiba speciosa & 1 & 2 & 0,12 & 2 & 0,2 & 0,0206 & 0,05 & 0,09 & 0,12 \\
\hline Tibouchina granulosa & 1 & 2 & 0,12 & 2 & 0,2 & 0,02 & 0,05 & 0,09 & 0,12 \\
\hline Prunus sellowii & 1 & 2 & 0,12 & 2 & 0,2 & 0,0184 & 0,05 & 0,09 & 0,12 \\
\hline Phyllostemonodaphini geminiflora & 1 & 2 & 0,12 & 2 & 0,2 & 0,0184 & 0,05 & 0,09 & 0,12 \\
\hline Eugenia cerasiflora & 1 & 2 & 0,12 & 2 & 0,2 & 0,0139 & 0,04 & 0,08 & 0,12 \\
\hline Ocotea corymbosa & 1 & 2 & 0,12 & 2 & 0,2 & 0,0134 & 0,03 & 0,08 & 0,12 \\
\hline Tapirira guianensis & 1 & 2 & 0,12 & 2 & 0,2 & 0,0129 & 0,03 & 0,08 & 0,12 \\
\hline Croton urucurana & 1 & 2 & 0,12 & 2 & 0,2 & 0,012 & 0,03 & 0,08 & 0,12 \\
\hline Aiouea trinervis & 1 & 2 & 0,12 & 2 & 0,2 & 0,0116 & 0,03 & 0,08 & 0,12 \\
\hline Himatanthus phagedaenicus & 1 & 2 & 0,12 & 2 & 0,2 & 0,0116 & 0,03 & 0,08 & 0,12 \\
\hline Eugenia brasiliensis & 1 & 2 & 0,12 & 2 & 0,2 & 0,0108 & 0,03 & 0,08 & 0,12 \\
\hline Ocotea acutifolia & 1 & 2 & 0,12 & 2 & 0,2 & 0,0108 & 0,03 & 0,08 & 0,12 \\
\hline Tapirira marchandii & 1 & 2 & 0,12 & 2 & 0,2 & 0,0104 & 0,03 & 0,08 & 0,11 \\
\hline Cassia ferruginea & 1 & 2 & 0,12 & 2 & 0,2 & 0,01 & 0,03 & 0,07 & 0,11 \\
\hline Maytenus evonymoides & 1 & 2 & 0,12 & 2 & 0,2 & 0,0093 & 0,02 & 0,07 & 0,11 \\
\hline Symplocos pubescens & 1 & 2 & 0,12 & 2 & 0,2 & 0,0088 & 0,02 & 0,07 & 0,11 \\
\hline Calyptranthes sp. & 1 & 2 & 0,12 & 2 & 0,2 & 0,0084 & 0,02 & 0,07 & 0,11 \\
\hline Guarea grandifolia & 1 & 2 & 0,12 & 2 & 0,2 & 0,0077 & 0,02 & 0,07 & 0,11 \\
\hline Endlicheria glomerata & 1 & 2 & 0,12 & 2 & 0,2 & 0,007 & 0,02 & 0,07 & 0,11 \\
\hline Guapira hirsuta & 1 & 2 & 0,12 & 2 & 0,2 & 0,007 & 0,02 & 0,07 & 0,11 \\
\hline Lonchocarpus muehlbergianus & 1 & 2 & 0,12 & 2 & 0,2 & 0,0067 & 0,02 & 0,07 & 0,11 \\
\hline Ocotea sp. & 1 & 2 & 0,12 & 2 & 0,2 & 0,0064 & 0,02 & 0,07 & 0,11 \\
\hline
\end{tabular}


Quadro 2 - Cont.

Table 2-Cont.

\begin{tabular}{lcccrrrrrr}
\hline Espécie & NI & DA & DR & FA & FR & DoA & DoR & VC\% & VI\% \\
\hline Carpotroche brasiliensis & 1 & 2 & 0,12 & 2 & 0,2 & 0,0064 & 0,02 & 0,07 & 0,11 \\
Myrcia sp2 & 1 & 2 & 0,12 & 2 & 0,2 & 0,0064 & 0,02 & 0,07 & 0,11 \\
Agonandra englerii & 1 & 2 & 0,12 & 2 & 0,2 & 0,0057 & 0,01 & 0,07 & 0,11 \\
Jacaratia spinosa & 1 & 2 & 0,12 & 2 & 0,2 & 0,0057 & 0,01 & 0,07 & 0,11 \\
Myrciafalax & 1 & 2 & 0,12 & 2 & 0,2 & 0,0054 & 0,01 & 0,07 & 0,11 \\
Psychotria nuda & 1 & 2 & 0,12 & 2 & 0,2 & 0,0052 & 0,01 & 0,07 & 0,11 \\
Myrtaceae sp. 2 & 1 & 2 & 0,12 & 2 & 0,2 & 0,0052 & 0,01 & 0,07 & 0,11 \\
Guarea kultiana & 1 & 2 & 0,12 & 2 & 0,2 & 0,0052 & 0,01 & 0,07 & 0,11 \\
Clusiaceae sp. 1 & 1 & 2 & 0,12 & 2 & 0,2 & 0,0046 & 0,01 & 0,07 & 0,11 \\
Ocotea cf suaveoloens & 1 & 2 & 0,12 & 2 & 0,2 & 0,0036 & 0,01 & 0,07 & 0,11 \\
\hline
\end{tabular}

Guapira opposita, Croton hemiargyreus e Eugenia leptoclada ocuparam as primeiras posições em valor de importância, principalmente devido à densidade e freqüência, pois a dominância foi considerada baixa, em comparação com outras espécies.

O índice de diversidade de Shannon (H') para a área estudada foi de 3,52 e a equabilidade (J'), de 0,696. Segundo Meira Neto e Martins (2000), o índice de diversidade varia entre 3,2 e 4,2 e, a equabilidade (J), entre 0,73 e 0,88, nas florestas estacionais semidecíduas em Minas Gerais. Portanto, a julgar pelo que afirmaram esses autores, o índice de diversidade para a área estudada foi considerado médio e a equabilidade, baixa.

A equabilidade e o índice de diversidade auxiliam muito a caracterização de comunidades vegetais; Martins (1993) afirmou que o índice de diversidade de Shannon é influenciado pela amostragem, porém oferece boa indicação da diversidade específica e pode servir para comparar florestas em locais distintos.

Silva et al. (2000) comentaram que a comparação de diferentes índices de diversidade deve ser avaliada com cuidado, uma vez que vários fatores inerentes à sucessão e ao método de amostragem podem interferir nos seus valores. Entre estes, destacam-se o número de espécies, de indivíduos por espécie e de espécies raras na amostragem e o total de indivíduos, além dos tipos de mosaicos abrangidos pela amostragem ou o grau de maturidade do compartimento analisado e o critério de inclusão adotado, dentre outros.

Dez espécies contribuíram com mais da metade dos indivíduos amostrados $(52,49 \%)$, indicando alta dominância, restando 146 espécies para a composição da outra metade dos indivíduos amostrados (excetuandose os mortos). Cabe ressaltar o destaque de Euterpe edulis em densidade, o que contribuiu para a baixa equabilidade, encontrada nessa amostra.

Essa grande ocorrência de Euterpe edulis deveuse, possivelmente, às exigências dessa espécie, no que se refere a água, sombreamento e fertilidade do solo, condições essas oferecidas pela ravina.

Em outros trabalhos realizados na microrregião de Viçosa, Paula (1999) considerou o valor encontrado para o índice de diversidade como médio, mesmo tendo em conta que o fragmento estivesse em estágio secundário de sucessão.

Marangon (1999) encontrou um valor alto para a riqueza florística e discutiu a hipótese de que a alta diversidade pode ter sido atribuída à forma de distribuição das unidades amostrais.

Meira Neto e Martins (2000) e Sevilha et al. (2001) encontraram valores altos para o índice de diversidade e a eqüabilidade, indicando que, além da riqueza florística, houve distribuição do número de indivíduos pelas muitas espécies com tendência à igualdade, o que evidencia a alta heterogeneidade do componente arbóreo.

\section{CONCLUSÕES}

Os resultados evidenciaram a importância da conservação do fragmento em estudo como fonte de germoplasma e por apresentar cinco espécies consideradas ameaçadas de extinção na Lista Vermelha das Espécies Ameaçadas de Extinção da Flora de Minas Gerais (MENDONÇA e LINS, 2000): Brosimum glaziovii, Dalbergia nigra, Euterpe edulis, Ocotea odorifera e Pisonia ambígua. Também por se tratar também de uma área que conserva boa parte da estrutura primitiva de uma Floresta Estacional Semidecídua. 


\section{AGRADECIMENTOS}

Aos proprietários do Sítio Bom Sucesso e aos especialistas que auxiliaram a identificação do material botânico: Gilberto Pedralli (in memoriam) (Lauraceae) e Flávia Cristina Pinto Garcia (gênero Inga).

\section{REFERÊNCIAS BIBLIOGRÁFICAS}

ALMEIDA, D. S.; SOUZA, A. L. Florística de um fragmento de Floresta Atlântica, no município de Juiz de Fora, Minas Gerais. Revista Árvore, v. 21, n. 2, p. 221-230, 1997.

AUBRÉville, A. As florestas do Brasil estudo fitogeográfico florestal. Anuário Brasileiro de Economia Florestal, v. 11, n. 1, p. 201-232, 1959.

BROWER, J. E.; ZAR., J. H. Field and laboratory methods for general ecology. 2.ed. Iowa: Wm. C. Brown, 1984. 226 p.

BRUMitT, R. K.; POWELL, C. E. Authors of plant names. Whitstable, Kent: Royal Botanic Gardens - Kew, Whitstable Litho, 1992. 732 p.

CRONQUIST, A. The evolution and classification of flowering plants. 2.ed. New York: Botanical Garden, 1988. 555 p.

\section{DEPARTAMENTO NACIONAL DE} METEOROLOGIA. Normais

Climatológicas (1961-1990). Brasília: SPI, Embrapa, 1992. 85 p.

GOMES, A. P. C. Critérios e indicadores de sustentabilidade para o manejo de uma floresta estacional semidecidual. 2000. 110 f. Dissertação (Mestrado em Ciência Florestal) - Universidade Federal de Viçosa, Viçosa, MG, 2000.

GUERRA, A. J. T.; CUNHA, S. B.

Geomorfologia: Uma atualização de bases e conceitos. Rio de Janeiro: Bertrand Brasil, 1995. $472 \mathrm{p}$.

LOPES, W. P. et al. Composição da flora arbórea de um trecho de Floresta Estacional no Jardim Botânico da Universidade Federal de Viçosa (face sudeste), Viçosa, Minas Gerais. Revista Árvore, v. 26, n. 3, p. 339-347, 2002.
MARANGON, L. C. Florística e fitossociologia de área de floresta estacional semidecidual visando dinâmica de espécies florestais arbóreas no município de Viçosa, MG. 1999. 135 f. Tese (Doutorado em Ecologia e Recursos Naturais) - Universidade Federal de São Carlos, São Carlos, 1999.

MARANGON, L. C.; SOARES, J. J.; SELICIANO, A. L. P. Florística arbórea da Mata da Pedreira no município de Viçosa, MG. Revista Árvore, v. 27, n. 2, p. 207-215, 2003.

MARTINS, F. R. Estrutura de uma floresta mesófila. Campinas: Universidade de Campinas, 1993. 246p.

MEIRA NETO, J. A. A. et al. Estrutura de uma floresta estacional aluvial em área diretamente afetada pela usina hidrelétrica de Pilar, Ponte Nova, Zona da Mata de Minas Gerais. Revista Árvore, v. 21, n. 2, p. 213-219, 1997a.

MEIRA NETO, J. A. A. et al. Estrutura de uma floresta estacional semidecidual submontana em área diretamente afetada pela usina hidrelétrica de Pilar, Ponte Nova, Zona da Mata de Minas Gerais. Revista Árvore, v. 21, n. 3, p. 337-344, 1997b.

MEIRA NETO, J. A. A. et al. Estrutura de uma floresta estacional semidecidual insular em área diretamente afetada pela usina hidrelétrica de Pilar, Ponte Nova, Zona da Mata de Minas Gerais. Revista Árvore, v. 21, n. 4, p. 493-500, 1997c.

MEIRA NETO, J. A. A. et al. Estrutura de uma floresta estacional semidecidual aluvial em área de influência da usina hidrelétrica de Pilar, Ponte Nova, Zona da Mata de Minas Gerais. Revista Árvore, v. 22, n. 1, p.179-184, 1998.

MEIRA NETO, J. A. A.; MARTINS, F. Estrutura da Mata da Silvicultura, uma floresta Estacional Semidecidual Montana no município de Viçosa - MG. Revista Árvore, v. 24,n. 2, p. 151-160, 2000.

MEIRA NETO, J. A. A.; MARTINS, F. Composição florística de uma floresta estacional Semidecidual Montana no município de Viçosa - MG. Revista Árvore, n. 26, v. 4, p. 437-446, 2002.

R. Árvore, Viçosa-MG, v.30, n.6, p.1045-1054, 2006 
MENDONÇA, M. P.; LINS, L. V. Lista vermelha das espécies ameaçadas de extinção da Flora de Minas Gerais. Belo Horizonte: Fundação Biodiversitas, 2000. 160 p.

MISSOURI BOTANICAL GARDEN. Disponível em: http:www.mobot.org/W3T/search/vast html. Acesso em: 05/03/2006.

MUELLER-DOMBOIS, D.; ELLENBERG, H. Aims and methods of vegetation ecology. New York: Willey \& Sons, 1974. 574 p.

PANIAGO, M. C. T. Evolução histórica e tendências de mudanças sócioeconômicas na comunidade de Viçosa - MG. 1983. 113 f. Dissertação (Mestrado em Extensão Rural) - Universidade Federal de Viçosa, Viçosa, MG, 1983.

PAUlA, A. Alterações florísticas e fitossociológicas da vegetação arbórea em uma floresta estacional semidecidual em Viçosa - MG. 1999. 87 f. Dissertação (Mestrado em Botânica) Universidade Federal de Viçosa, Viçosa, MG, 1999.

PIELOU, E. C. Ecological diversity. New York: Willey, 1975.165 p.

RIBAS, F. R. et al. Composição florística de dois trechos em diferentes etapas serais de uma Floresta Estacional Semidecidual em Viçosa, Minas Gerais. Revista Árvore, v. 27, n. 6, p. 821-830, 2003.

SENRA, L. C. Composição florística e estrutura fitossociológica de um fragmento florestal da fazenda Rancho Fundo, na Zona da Mata - Viçosa, MG. 2000. 66 f. Dissertação (Mestrado em Botânica) - Universidade Federal de Viçosa, Viçosa, MG, 2000.
SEVILHA, C. S. et al. Fitossociologia do estrato arbóreo de um trecho de floresta estacional no Jardim Botânico da Universidade Federal de Viçosa (face sudoeste), Viçosa, Minas Gerais. Revista Árvore, v. 25, n. 4, p. 431-443, 2001.

SHEPHERD, G. J. Fitopac 1: Manual do usuário. Campinas: Universidade Estadual de Campinas, 1996. 96 p.

SILVA, A. F.; FONTES, N. R. L.; LEITÃO FILHO, H. F. Composição florística e estrutura horizontal do estrato arbóreo de um trecho da Mata da Biologia da Universidade Federal de Viçosa. Revista Árvore, v. 24, n. 4, p. 397-406, 2000.

SILVA, N. R. S. et al. Composição florística e estrutura de uma floresta estacional semidecidual montana em Viçosa, MG. Revista Árvore, v. 28, n. 3, p. 397-405, 2004.

\section{SOARES JÚNIOR, F. J. Composição}

florística e estrutura de um fragmento de floresta estacional semidecidual na Fazenda Tico-Tico, Viçosa, MG. 2000. 68 f. Dissertação (Mestrado em Botânica) Universidade Federal de Viçosa, Viçosa, MG, 2000.

VELOSO, H. P.; RANGEL FILHO, A. L. R.; LIMA, J. C. Classificação da vegetação brasileira, adaptada a um sistema universal. Rio de Janeiro: IBGE, 1991. 123 p.

VIANA, V. M. Biologia e manejo de fragmentos de florestas naturais. In: CONGRESSO FLORESTAL BRASILEIRO, 6.; 1990, São Paulo. Anais.... São Paulo: Sociedade Brasileira de Silvicultura, 1990. p. 113-118.

VOLPATO, M. M. L. Regeneração natural em uma floresta secundária no domínio de Mata Atlântica: uma análise fitossociológica. 1994. $123 \mathrm{f}$. Dissertação (Mestrado em Ciência Florestal) Universidade Federal de Viçosa, Viçosa, MG, 1994. 